\title{
HUBUNGAN ANTARA IKLIM ORGANISASI DENGAN KEPUASAN KERJA PADA KARYAWAN PT CIPTA NIAGA SEMESTA CABANG BEKASI
}

\author{
Dea Fauzia Ridlwan* \\ Rr Ponco Dewi K.*
}

\begin{abstract}
The purpose of this research is to detect correlation between climate organization with job satisfaction on employees PT Cipta Niaga Semestat. The research is done during for two months since April until Mai 2014. The method of research is survey method with correlation approach. The population research was all of employees with total 60 employees, and 51 employees for sampling and used simple random sampling. Instrument that used to get variable data $X$ (Climate Organization) measured by questionnaire using Likert Scale. For Variable Y (Job Satisfaction) was also measured by questionnaire using Likert Scale. The analysis test by finding regression equation, that is $\hat{Y}=$ $35,58+0,513 \mathrm{X}$, while analysis rules test that is test normalitas while analysis rules test that is test normalitas regression estimation error $Y$ on $X$ with test liliefors got Lhitung0,090 < Ltabel 0,124, matters this means sample comes from population normal distribution. Significancy test and regression linearity by using analysis table varians (anava) got regression similarity Fhitung 25,12 > Ftabel 4,14 that declare regression very mean with regression linearity test that produce Fhitung 0,85 < Ftabel 2,0 that show that regression model that used linear. Correlation coefficient hypothesis test is done with formula product moment produce rxy as big as 0,582. Significancy test with thitung as big as 5,01 dan ttabel 1,68. Because tcount < ttabel, from watchfulness result so researcher can conclude that found connection significant between climate organization with job satisfaction on employee PT Cipta Niaga Semesta. Determination coefficient test produces KD as big as 33,89\%. So can be taken conclusion found which are positive connection and significant between climate organization and job satisfaction.
\end{abstract}

Keywords : Job Satisfaction, Climate Organization 


\section{PENDAHULUAN}

Saat ini seluruh bangsa di dunia sedang berada dalam era yang di kenal dengan era globalisasi. Era ini di tandai dengan berbagai macam perkembangan ilmu pengetahuan dan teknologi. Perubahan dan kemajuan yang terjadi di berbagai bidang, memberikan dampak pada setiap organisasi di dalam perusahaan untuk siap dan mampu berkompetisi dengan organisasi lainnya. Sehingga, dengan perubahan dan kemajuan yang semakin kompleks, menuntut setiap organisasi untuk mengelola sumber daya yang dimiliki dengan sebaik mungkin agar perusahaan sanggup bertahan dan terus berkembang.

Organisasi yang berkembang membutuhkan sumber daya manusia yang dapat dikembangkan pula. Selain itu, organisasi juga membutuhkan sumber daya manusia yang berkualitas karena sumber daya manusia yang berkualitas merupakan salah satu faktor penting yang dapat menggerakkan dan mengembangkan perusahaan. Sumber daya manusia dalam hal ini adalah karyawan. Karyawan adalah mahluk sosial yang menjadi aset utama bagi setiap perusahaan. Mereka menjadi perencana, pelaksana, dan pengendali yang selalu berperan aktif dalam mewujudkan tujuan perusahaan. Oleh karena itu, setiap organisasi

\footnotetext{
* Dea Fauzia Ridlwan \& Rr. Ponco Dewi K. Fakultas Ekonomi Universitas Negeri Jakarta.
}

harus berusaha agar karyawannya bekerja secara efektif dan efisien dengan memenuhi segala kebutuhan karyawan tersebut.

Karyawan merupakan aset perusahaan yang sangat berharga yang harus dikelola dengan baik oleh perusahaan agar dapat memberikan kontribusi yang optimal. Salah satu hal yang harus menjadi perhatian utama perusahaan adalah kepuasan kerja para karyawannya. Seseorang yang merasakan kepuasan dalam bekerja tentunya akan berupaya semaksimal mungkin untuk memberikan performa terbaiknya kepada organisasi tempat ia bekerja dengan menyelesaikan tugas pekerjaannya sebaik mungkin. Dengan demikian produktivitas dan hasil kerja pegawai akan meningkat secara optimal.

Karyawan yang tidak puas mereka akan merasa tidak nyaman dalam bekerja, merasa kurang dihargai, dan tidak bisa mengembangkan segala potensi yang mereka miliki, sehingga secara otomatis karyawan tidak dapat fokus dan berkonsentrasi secara penuh terhadap pekerjaannya. Selain itu, bila karyawan dalam suatu perusahaan tidak mendapatkan suatu kepuasan maka mereka akan cenderung berperilaku tidak puas dalam kerja seperti aksi demonstrasi, aksi mogok, dan aksi mangkir kerja.

Ada beberapa faktor yang dapat mempengaruhi kepuasan kerja karyawan antara lain: motivasi 
kerja, stres kerja, pengembangan karier, komunikasi antara atasan dan bawahan, dan iklim organisasi.

Salah satu faktor yang mempengaruhi kepuasan kerja adalah motivasi kerja karyawan. Motivasi kerja adalah faktor penggerak dalam diri seseorang yang akan mengarahkan perilaku dan prestasi kerja orang tersebut. Dengan adanya motivasi kerja, membuat karyawan menjadi lebih bersemangat dalam melakukan pekerjaan dan dapat meningkatkan kinerjanya. Namun pada kenyataannya di setiap perusahaan pasti ada beberapa karyawan masih memiliki motivasi kerja yang rendah. Hal ini terjadi ketika karyawan merasa tidak nyaman dengan kondisi lingkungan tempat dimana mereka bekerja dan kurangnya pengawasan dari atasan. Padahal motivasi kerja itu sangat di butuhkan, karena motivasi kerja yang tumbuh dari dalam diri karyawan yang tinggi akan meningkatkan kinerja serta kepuasan yang dalam menyelesaikan suatu pekerjaannya. Sebaliknya jika motivasi kerja karyawan rendah akan menurunkan kinerja dan kepuasan dalam menyelesaikan suatu pekerjaan. Oleh karena itu, tanpa motivasi, kepuasan kerja tidak akan meningkat.

Stres kerja juga merupakan salah satu faktor yang sangat mempengaruhi kepuasan kerja karyawan. Tuntutan target pekerjaan dapat mengakibatkan situasi stres kerja pada karyawan yang akhirnya akan berdampak pada kepuasan kerja. Belakangan ini pekerja di Indonesia banyak tertekan karena karyawan dituntut untuk bekerja dengan waktu yang sangat ketat, dibawah pengawasan dan tekanan yang akan menimbulkan stres. Tingkat stres kerja yang tinggi juga di alami oleh karyawan di perusahaan PT Cipta Niaga Semesta. Setiap karyawan terutama sales, baik sales kanvas motor maupun kanvas mobil memiliki tuntutan target yang tinggi di luar kemampuan mereka. Ditambah lagi kondisi lingkungan yang tidak menentu terkadang panas dan hujan disertai macet. Dengan bertambahnya tingkat stres kerja pada karyawan, maka akan menurunkan tingkat kepuasan kerja karyawan.

Faktor lain yang berpengaruh terhadap kepuasan kerja karyawan adalah pengembangan karier. Setiap sumber daya manusia diberi kesempatan untuk mengembangkan karier serta kemampuannya secara optimal. Pengembangan karier merupakan hal yang penting dimana manajemen dapat meningkatkan produktivitas, meningkatkan sikap karyawan terhadap pekerjaannya dan membangun kepuasan kerja yang lebih tinggi. Namun, terkadang tidak sesuai dengan ketentuan yang berlaku dimana tidak adanya kesempatan karyawan untuk mengembangkan karier karena kurangnya program pengembangan karier di perusahaan tersebut dan 
atasan seringkali membeda-bedakan karyawan dalam melakukan penilaian prestasi kerja sehingga karyawan malas bekerja, hal ini menyebabkan kepuasan kerja karyawan menurun.

Komunikasi antara pimpinan dan bawahan juga dapat mempengaruhi tingkat kepuasan kerja karyawan. Di antara pimpinan dan karyawan harus ada komunikasi dua arah sehingga terjalinnya komunikasi yang baik antara kedua belah pihak. Dengan adanya penerimaan dan penyampaian informasi yang benar menjadikan komunikasi lancar merupakan salah satu penunjang untuk mendapatkan kepuasan kerja karyawan. Namun, terkadang para pimpinan tidak begitu memperhatikan arus komunikasi ke bawah yang menyebabkan kurangnya komunikasi yang terjalin antara pimpinan dengan karyawannya. Hal ini terjadi karena kurangnya sifat terbuka pimpinan terhadap karyawannya sehingga pimpinan hanya mau memberikan informasi kebawah bila mereka merasa pesan itu penting bagi penyelesaian tugas. Selain itu, biasanya pimpinan lebih banyak menyampaikan pesan secara tertulis daripada pesan yang disampaikan secara lisan dan tatap muka. Apalagi sekarang ini perkembangan alat komunikasi sudah semakin maju, sehingga jarang sekali pimpinan menyampaikan pesan secara langsung. Dengan kurangnya arus komunikasi yang terjalin antara pimpinan dan karyawannya akan menimbulkan karyawan menjadi tidak bersemangat dalam bekerja sehingga dapat menurunkan kepuasan kerja karyawan.

Untuk dapat mencapai tujuan perusahaan yang telah direncanakan, perlu ada kerjasama yang baik antara seluruh komponen yang terdapat di dalam perusahaan sehingga dapat meningkatkan produktifitas kerja. Untuk itu perlu di ciptakan iklim organisasi yang kondusif. Iklim organisasi merupakan faktor penting yang dapat mempengaruhi kepuasan kerja karyawan. Namun beberapa perusahaan masih memiliki iklim organisasi yang kurang kondusif. Dengan iklim organisasi yang kurang kondusif tesebut dapat menurunkan tingkat kepuasan kerja para karyawannya.

PT Cipta Niaga Semesta merupakan distributor makanan dan minuman, mengalami permasalahan mengenai tingkat kepuasan kerja karyawan yang dikaitkan dengan iklim organisasi yang ada pada perusahaan tersebut. Hal tersebut ditandai dengan rendahnya dukungan pimpinan kepada karyawan dalam bekerja sehingga tanggung jawab karyawan dalam menyelesaikan pekerjaanpun rendah. Dengan demikian karyawan tidak dapat maksimal dalam menyelesaikan pekerjaannya. Dengan rendahnya dukungan dan perhatian perusahaan kepada karyawan menyebabkan komitmen karyawan di perusahaan rendah yang menyebabkan karyawan tidak 
merasa menjadi bagian dari perusahaan. Hal ini dibuktikan dengan karyawan yang ada di perusahaan khususnya dibagian sales sering sekali mengundurkan diri sehingga tingkat keluar masuk karyawan tinggi. Padahal sudah semestinya perusahaan menciptakan iklim organisasi yang kondusif yaitu dengan memberikan dukungan dan perhatian kepada karyawannya sehingga karyawan merasa lebih diperhatikan dan dapat meningkatkan kepuasan kerja karyawan.

\section{KAJIAN TEORETIS \\ Kepuasan Kerja}

Kepuasan kerja merupakan hal yang bersifat individual karena setiap individu akan memiliki tingkat kepuasan yang berbeda-beda sesuai dengan nilai-nilai yang berlaku dalam diri setiap individu.

Handoko mengemukakan, "kepuasan kerja mencerminkan perasaan seseorang terhadap pekerjaannya". (Handoko, 2001)

Toni Setiawan,"kepuasan kerja akan tampak dalam sikap positif pekerja atas segala sesuatu yang dihadapi lingkungan kerja terhadap pekerjaannya". (Toni Setiawan, 2012)

Noe at. el. menyatakan bahwa "job statisfication as pleasurable feeling that result from the perception that one's job fulfillment of one's important job value".(Wilson Bangun, 2012)

Dapat di artikan bahwa kepuasan kerja sebagai perasaan senang yang dihasilkan dari persepsi bahwa pemenuhan pekerjaan seseorang dari satu nilai tugas penting. Perasaan senang atau tidak akan muncul dari hasil penilaian atas pekerjaan yang mereka lakukan.

Dalam buku Organizational Behavior, Fred Luthan menyatakan: "through the years five job dimension have been identified to represent the most important characteristics of a job about which people have affective responses. There are:

1. The work itself. The extent to which the job provides the individual with interesting tasks, opportunities for learning, and the chance to accept responsibility.

2. Pay. The amount of financial remuneration that is received and the degree to which this is viewed ad equitable vis-a-vis that of others in the organization

3. Promotion opportunities. The chances for advancement in the organization

4. Supervision. The abilities of the workers are technically proficient and behavioral support

5. Coworkers. The degree to which fellow workers are technically proficient and socially supportiv. ( Fred Luthans,2005)

Dapat di artikan bahwa terdapat lima dimensi yang telah diidentifikasi untuk merepresentasikan karakteristik pekerjaan yang paling penting dimana karyawan memiliki respons afektif, lima dimensi tersebut adalah: 
1. Pekerjaan itu sendiri, seberapa besar pekerjaan itu memberi seseorang tugas yang menarik, kesempatan untuk belajar dan kesempatan untuk menerima tanggung jawab.

2. Gaji dan upah, seberapa besar imbalan financial yang diterima dan seberapa besar hal itu dianggap pantas atau adil dibandingkan dengan imbalan di organisasi lain.

3. Kesempatan promosi, kesempatan maju dalam organisasi.

4. Pengawasan, kemampuan supervisor untuk memberikan bantuan teknis dan dukungan moral dapat meningkatkan kepuasan kerja.

5. Rekan sekerja, seberapa besar rekan kerja trampil secara teknis dan secara sosial memberi dukungan.

Menurut the value percept theory cara mengukur kepuasan (job satisfaction) melalui:

(1) Pay Satisfaction,

(2) Promotion Satisfaction,

(3) Supervision Satisfaction,

(4) Coworker Satisfaction,

(5) Satisfaction with the Work Itself (Wibowo, 2013)

Dari teori-teori di atas yang telah dikemukakan oleh para ahli dapat disimpulkan bahwa kepuasan kerja merupakan perasaan dan sikap positif seseorang mengenai pekerjaannya. Dari beberapa faktor yang dikemukakan oleh ahli diatas, ada lima faktor yang dapat mempengaruhi kepuasan kerja karyawan yaitu pekerjaan itu sendiri, gaji, promosi jabatan, pengawasan (supervisi), dan rekan kerja.

\section{Iklim Organisasi}

Iklim organisasi juga merupakan faktor penting yang menentukan kehidupan suatu organisasi.

Menurut Davis yang dimaksud dengan iklim organisasi adalah : "the human environment within an organization's employees do their work". (Husaini Usman,2013)

Dapat di artikan bahwa iklim organisasi adalah lingkungan manusia di dalam suatu organisasi tempat mereka melaksanakan pekerjaannya. Dalam melaksanakan pekerjaan, iklim sangat mempengaruhi segala hal yang bekerja dalam suatu organisasi.

Tiguri mendefinisikan iklim organisai sebagai :

"Organizational climate is relatively enduring quality of the internal environtment of an organization that is (a) experienced by its members, (b) influence their behavior, and (c) can be described in terms of values of its particular set of characteristics (or attributes) of the organization". ( Achmad Sobirin,2009).

Diartikan bahwa iklim organisasi adalah kualitas lingkungan organisasi yang (a) dirasakan dan dialami oleh para anggota organisasi, (b) yang mempengaruhi prilaku mereka, dan (c) yang bisa 
dijelaskan dalam bentuk satu set karakteristik atau atribut organisasi.

Hillrienger dan Slocum

mengemukakan definisi iklim

organisasi dengan

mempertimbangkan subsistem

dalam organisasi. Mereka mengatakan bahwa, "iklim organisasi adalah suatu set atribut organisasi dan subsistemnya yang dapat dirasakan oleh anggota organisasi, yang mungkin disebabkan oleh cara-cara organisasi atau subsistem, terhadap anggota dan ligkungannya".(Arni Muhammad, 2002)

Menurut Robert Stinger, untuk mengukur iklim organisasi terdapat enam dimensi yang diperlukan sebagai berikut:

a. Struktur (structure)

b. Standar-standar (standards)

c. Tanggung jawab (responsibility)

d. Penghargaan (recognition)

e. Dukungan (support)

f. Komitmen (commitement) (Wirawan, 2007).

Sedangkan James, L.R., \& Sells, S.B mengemukakan dimensi-dimensi iklim organisasi sebagai berikut:

a. Dimensi struktur (structure)

b. Dimensi tanggungjawab (responsibility)

c. Dimensi kehangatan - dukungan (warmth and support)

d. Dimensi imbalan-sanksi (reward and punishment)

e. Dimensi konflik (conflict)

f. Dimensi risiko (risk)

g. Dimensi identitas organisasi \& loyalitas kelompok (organizational identity and group loyality).

\section{(Ayi Karyana,2012}

Jadi, dari beberapa pendapat tersebut iklim organisasi merupakan kualitas lingkungan yang dialami dan dirasakan oleh anggota-anggota organisasi yang mempengaruhi prilaku dan tingkah laku mereka yang dapat diuraikan dalam bentuk suatu set karakteristik atau atribut organisasi.

\section{HASIL PENELITIAN}

Analisis regresi linier data penelitian iklim organisasi dengan kepuasan kerja menghasilkan arah regresi sebesar 0,513 dan konstanta sebesar 35,58. Dengan demikian bentuk hubungan antara iklim oganisasi dengan kepuasan kerja mempunyai persamaan regresi $\hat{Y}=$ $35,58+0,513 X$. Persamaan regresi ini menggambarkan setiap peningkatan satu skor iklim organisasi akan menyebabkan peningkatan kepuasan kerja sebesar 0,513 pada konstanta 35,58.

Uji koefisien korelasi digunakan untuk mengetahui besar atau kuatnya hubungan antara iklim organisasi dengan kepuasan kerja. Untuk itu digunakan rumus koefisien korelasi product moment dari Pearson. Dari hasil perhitungan penelitian ini, diperoleh $r_{\text {hitung }}$ ( $r x y$ ) sebesar 0,582. Untuk uji signifikan koefisien korelasi disajikan pada tabel I

\section{Tabel I Pengujian signifikansi Koefisien Korelasi antara X dan $\mathbf{Y}$}


Dea Fauzia Ridlwan \&: Hubungan Antara IKlim Organisasi Dengan Kepuasan Kerja Pada Karyawan PT Cipta

\begin{tabular}{|c|c|c|c|c|}
\hline $\begin{array}{c}\text { Korel } \\
\text { asi } \\
\text { Antar } \\
\text { a }\end{array}$ & $\begin{array}{l}\text { Koefisi } \\
\text { en } \\
\text { Korela } \\
\text { si }\end{array}$ & $\begin{array}{l}\text { Koefisien } \\
\text { Determin } \\
\text { asi }\end{array}$ & $\begin{array}{c}t_{\text {hitu }} \\
n g\end{array}$ & $\begin{array}{c}t_{\text {tab }} \\
\text { el } \\
a \\
= \\
0,0 \\
5\end{array}$ \\
\hline $\begin{array}{c}\text { X dan } \\
\text { Y }\end{array}$ & $0,582 *$ & $33,89 \%$ & $\begin{array}{c}5,0 \\
1\end{array}$ & $\begin{array}{c}1,6 \\
8\end{array}$ \\
\hline
\end{tabular}

Sumber: Diolah oleh Peneliti

Keterangan: $t_{\text {hitung }}>\mathrm{t}_{\text {tabel }}$ yaitu 5,01 $>1,68$

Nilai koefisien korelasi $r_{x y}$ sebesar 0,582 , dan thitung sebesar $5,1>t_{\text {tabel }}$ sebesar 1,68 , sehingga dapat disimpulkan bahwa terdapat hubungan positif antara iklim organisasi dengan kepuasan kerja. Nilai ini memberikan pengertian bahwa ada hubungan positif antara iklim organisasi dengan kepuasan kerja, semakin kondusif iklim organisasi di perusahaan maka semakin tinggi tingkat kepuasan kerja karyawan.

Adapun koefisien determinasi yaitu $r_{x y}{ }^{2}=\left(0,582^{2}\right)=0,3389$. Sehingga dapat dikatakan bahwa $33,89 \%$ variasi kepuasan kerja ditentukan oleh iklim organisasi, sedangkan sisanya dipengaruhi oleh faktor lain yang tidak diteliti dalam penelitian ini.

\section{KESIMPULAN}

Hasil penelitian yang dilakukan, diketahui terdapat hubungan positif dan signifikan antara iklim organisasi dengan kepuasan kerja pada karyawan PT Cipta Niaga Semesta. Kepuasan kerja pada karyawan PT Cipta Niaga Semesta dipengaruhi oleh iklim organisasi sebesar $33,89 \%$ dan $66,11 \%$ sisanya di pengaruhi oleh faktor lain yang tidak diteliti dalam penelitian ini

\section{DAFTAR PUSTAKA}

Bangun, Wilson. 2012. Manajemen Sumber Daya Manusia. Jakarta: Erlangga.

Handoko, T.Hani. 2001. Manajemen Personalia Dan Sumber Daya Manusia. Yogyakarta: BPFEYogyakarta.

Husaini, Usman. 2013. Manajemen Teori, Praktik, dan Riset Pendidikan, edisi 4. Jakarta:PT Bumi Aksara.

Karyana, Ayi. 2012. "Pengaruh Iklim Organisasi Terhadap Produktivitas Kerja Di Unit Pelaksana Teknis Kurikulum (UPT Kurikulum) Kecamatan Jasinga Kabupaten Bogor". Jurnal Ilmiah Administrasi Publik dan Pembangunan, Vol.3, No.1, Januari - Juni 2012

Luthans, Fred. 2005. Organizational Behavior. New York: McGrawHill/Irwin.

Muhammad, Arni. 2002. Komunikasi Organisasi. Jakarta: Bumi Aksara.

Setiawan, Toni. 2012. Manajemen Sumber Daya Manusia: Kinerja, Motivasi, Kepuasan Kejra dan Produktivitas. Jakarta : Platinum.

Sobirin, Achmad. 2009. Budaya Organisasi, Edisi Kedua. 
Dea Fauzia Ridlwan \&: Hubungan Antara IKlim Organisasi Dengan Kepuasan Kerja Pada Karyawan PT Cipta

Yogyakarta : Sekolah Tinggi Ilmu Manajemen YKPN.

Wibowo. 2009. Manajemen Kinerja Edisi Kedua. Jakarta: Rajawali Pers.
Wirawan. 2007. Budaya dan Iklim Organisasi: Teori Aplikasi dan Penelitia. Jakarta: Salemba Empat. 